\title{
Gastrointestinal Bleeding due to Arteriovenous Malformation of the Intestine
}

\author{
Wei-Peng Liu ${ }^{1,3}$, Yuan $\mathrm{Lu}^{1,2}$, Wei Liu ${ }^{1,2^{*}}$ \\ ${ }^{1}$ Institute of Digestive Disease, China Three Gorges University, Yichang, China \\ ${ }^{2}$ Department of Gastroenterology, Yichang Central People’s Hospital, Yichang, China \\ ${ }^{3}$ Department of Gastrointestinal Surgery, Yichang Central People’s Hospital, Yichang, China
}

*Correspondence to: Wei Liu; Institute of Digestive Disease, China Three Gorges University, Yichang, China; E-mail: liuwei@ctgu.edu.cn

Received: Jan 13 ${ }^{\text {th }}, 2021$; Accepted: Jan 17 $7^{\text {th }}, 2021$; Published: Jan $21^{\text {st }}, 2021$

Citation: Liu W-P, Lu Y, Liu W. Gastrointestinal bleeding due to arteriovenous malformation of the intestine. Gastro Open A Open J. $2021 ; 2$ (1): 43-44. doi: 10.33169/gastro.GOAOJ-2-109

\section{INTRODUCTION}

A 75-year-old woman presented with a 6-month history of bloody stool. She had no documented medical history and showed no signs of gastrointestinal disease. Laboratory tests and abdominal computed tomography were unremarkable. Double-balloon enteroscopy was performed after an initial negative esophagogastroduodenoscopy and colonoscopy. A double-balloon enteroscopy view showed oozing of blood from a miniscule point source on the jejunum mucosa (Figure A). Endoscopic treatment was ineffective because bleeding remained unchanged. Therefore, an exploratory laparotomy was performed which detected the localization of bleeding point from the mucosa marked by double-balloon en teroscopy (Figure B). The patient then underwent jejunal loca xcision and the bleeding point was completely removed (Figure C). I is a gic examination of the bleeding jejunum mucos $\mathrm{CO}_{4}$ rmed in equla expanded arteries and veins which were ogre ted the sul mucosal layer with a missing intervening car ary netu was no evidence of abnormal profifera on the ascular endothelial cells. And based on these indings, the $\mathrm{A}$ ient rec ved a diagnosis of arteriovenous malformat $\mathrm{n}$. Fi llly, the $\mathrm{f}$ tient recovered postoperatively. Arteriov ato malfo nation arises during embryogenesis which is relevant to orm nes and here uttary susceptibility. ${ }^{1}$ Arteriovenous malformation 1 ery ects the gastrointestinal tract, but the small intestine and right emicoron are the most common sites for gastrointestinal arteriovenoy. malformation. ${ }^{2,3}$ Most patients with suspected arteriovenous malformation present with sudden onset of middle intestinal or chronic recurrent bleeding. Infrequent symptoms of arteriovenous malformation include both anemia and tenesmus. It may be challenging to differentiate arteriovenous malformation from hemangioma with a high rate of misdiagnosis. ${ }^{4,5}$ Vascular anomalies are divided into hemangioma and vascular malformation according to histopathology and hydrodynamics. The presence of abnormal proliferation of vascular endothelial cells is the specific characteristic of arteriovenous malformation. Surgical resection remains the mainstay of arteriovenous malformation treatment because of ineffective pharmacologic options for treating arteriovenous malformation and a high recurrence rate of arterial embolization. Here we present a rare case of a terminal jejunal arteriovenous malformation in an aged woman whose first manifestation was active bleeding. Our report also highlights that this etiology should be considered when oozing of blood from a miniscule point source on the jejunum mucosa is visualized with at mm sal lesions although arteriovenous malformation may be di. cult to ce firm without histopathology. Figure 1: Gastrointest 1 bleeding due arterio nous malformation of the intestine. (A) Double-ball ent scon riew sh ing ozing of blood from a miniscule point source on t. ejunum $m$ osa; (B) A n ey coratory laparotomy detecting the localization of leedi point from the muc sa; (C) Jejunal local excision was performed and the eding po was comp removed (D) Histologic examination of the bleeding jejunum mucosa nfirmed irregularly expanded arteries and veins.

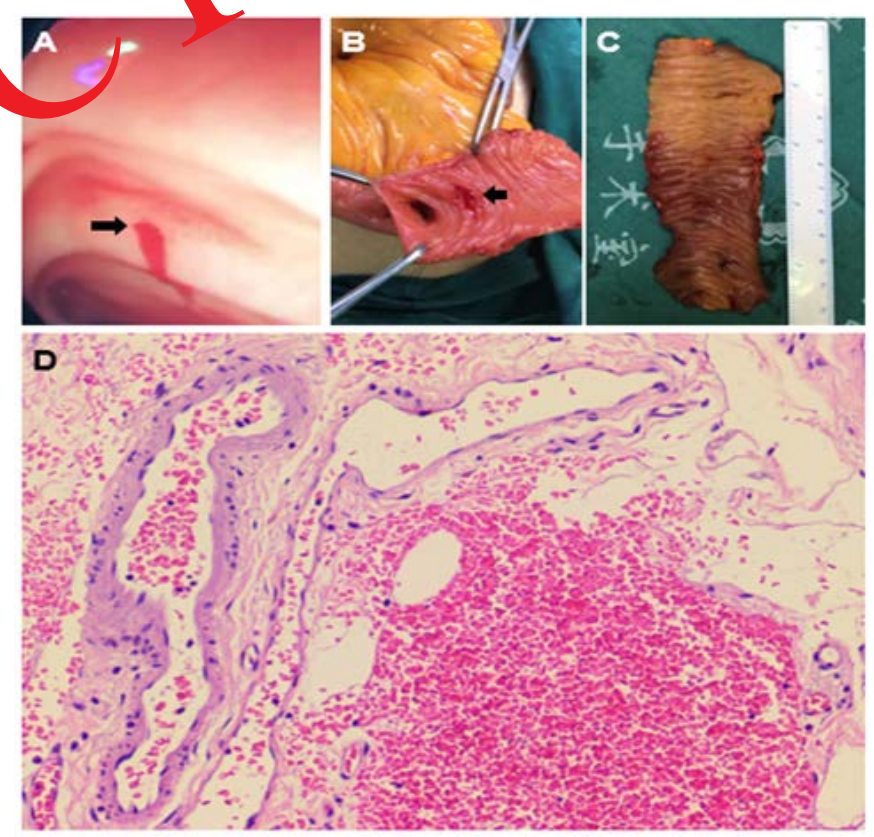

\section{FUNDING}

This work was supported by National Natural Science Foundation of China (31600134). 


\section{CONFLICTS OF INTEREST}

None.

\section{ETHICAL STATEMENT}

The authors are accountable for all aspects of the work in ensuring that questions related to the accuracy or integrity of any part of the work are appropriately investigated and resolved. Written informed consent was obtained from the patient for publication of this "Images in Clinical Medicine".

\section{REFERENCES}

1. Colletti G, Valassina D, Bertossi D, Melchiorre F, Verc "lio G, Br R. Contemporary management of vascular malformation > ral Ma lofac Surg. 2014; 72(3): 510-528. doi: 10.1016 ns.2013.
2. Yoo S. GI-Associated Hemangiomas and Vascular Malformations. Clin Colon Rectal Surg. 2011; 24(3): 193-200. doi: 10.1055/s-00311286003

3. Komekami Y, Konishi F, Murm, et al. Rectal arterio-venous malformation (AVM) with ble ing of an ternal hemorrhoid. Clin J Gastroenterol. 2016; 9(1) . 24-26. i: $10.10 /$ /s12328-016-0629-8

4. Mullil JB, Glow ki J. I mar giomas and vascular malformations in 11 ts and c dren: a clasorfication based on endothelial characteristics. I st Recon. Suro. 1982; 69(3): 412-422. doi: 10.1097/00006534$1982030-00002$

5. Shi T, Wang LT, Liu G. A terminal rectal mass ultimately identified by istopathology examination. Clin Gastroenterol Hepatol. 2018; 16(4): 23-A24. doi: 10.1016/j.cgh.2017.06.027

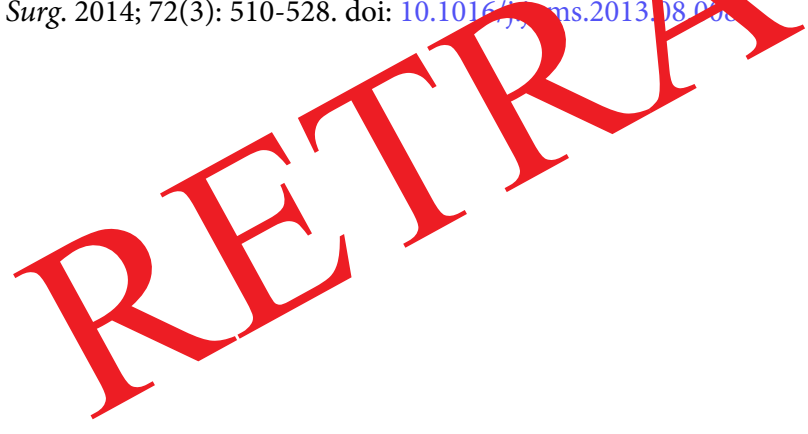

